Text S2. Plant vitality survey.

1. INTENSITY OF LEAF COLOR (high score indicates more intense color and photosynthesis potential; low score indicates discoloration and negative impact on the photosystem; however, intensification of color can represent toxic influence for which the plant tries to compensate).

\title{
Treatment: Clover
}

Tomato Variety:

Plant \# 1

$\begin{array}{lllll}0 & 1 & 2 & 3 & 4\end{array}$

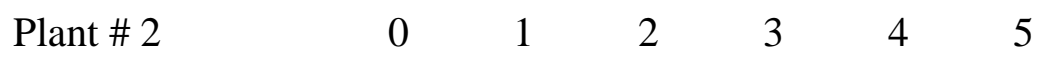

$\begin{array}{lllllll}\text { Plant \# } 3 & 0 & 1 & 2 & 3 & 4 & 5\end{array}$

$\begin{array}{llllllll}\text { Plant \# } 4 & 0 & 1 & 2 & 3 & 4 & 5\end{array}$

$\begin{array}{lllllll}\text { Plant \# } 5 & 0 & 1 & 2 & 3 & 4 & 5\end{array}$

\section{Treatment: Control}

Tomato Variety:

Plant \# 1

0

$\begin{array}{llllllll}\text { Plant \# } 2 & 0 & 1 & 2 & 3 & 4 & 5\end{array}$

$\begin{array}{lllllll}\text { Plant \# } 3 & 0 & 1 & 2 & 3 & 4 & 5\end{array}$

$\begin{array}{llllllll}\text { Plant \# } 4 & 0 & 1 & 2 & 3 & 4 & 5\end{array}$

$\begin{array}{lllllll}\text { Plant \# } 5 & 0 & 1 & 2 & 3 & 4 & 5\end{array}$

Treatment: Black Plastic

Tomato Variety:

$\begin{array}{lcccccc}\text { Plant \# 1 } & 0 & 1 & 2 & 3 & 4 & 5 \\ \text { Plant \# 2 } & 0 & 1 & 2 & 3 & 4 & 5 \\ \text { Plant \# 3 } & 0 & 1 & 2 & 3 & 4 & 5 \\ \text { Plant \# 4 } & 0 & 1 & 2 & 3 & 4 & 5 \\ \text { Plant \# 5 } & 0 & 1 & 2 & 3 & 4 & 5\end{array}$

2. PLANT STRENGTH / SUPPLENESS (considers wilting of leaves, stems, and flowers as a proxy for physiological processes) $1=$ very weak $5=$ strong 
Treatment: Clover

Tomato Variety:

Plant \# 1

$\begin{array}{lllll}0 & 1 & 2 & 3 & 4\end{array}$

$\begin{array}{lllllll}\text { Plant \# } 2 & 0 & 1 & 2 & 3 & 4 & 5\end{array}$

$\begin{array}{lllllll}\text { Plant \# } 3 & 0 & 1 & 2 & 3 & 4 & 5\end{array}$

$\begin{array}{lllllll}\text { Plant \# } 4 & 0 & 1 & 2 & 3 & 4 & 5\end{array}$

$\begin{array}{lllllll}\text { Plant \# } 5 & 0 & 1 & 2 & 3 & 4 & 5\end{array}$

Treatment: Control

Tomato Variety:

Plant \# 1

\begin{tabular}{lllll}
\hline 0 & 1 & 2 & 3 & 4
\end{tabular}

Plant \# 2

$\begin{array}{llllll}0 & 1 & 2 & 3 & 4 & 5\end{array}$

Plant \# 3

$\begin{array}{llllll}0 & 1 & 2 & 3 & 4 & 5\end{array}$

Plant \# 4

$\begin{array}{llllll}0 & 1 & 2 & 3 & 4 & 5\end{array}$

Plant \# 5

$\begin{array}{llllll}0 & 1 & 2 & 3 & 4 & 5\end{array}$

Treatment: Black Plastic

Tomato Variety:

Plant \# 1

$\begin{array}{llllll}0 & 1 & 2 & 3 & 4 & 5\end{array}$

Plant \# 2

$\begin{array}{llllll}0 & 1 & 2 & 3 & 4 & 5\end{array}$

Plant \# 3

$\begin{array}{llllll}0 & 1 & 2 & 3 & 4 & 5\end{array}$

Plant \# 4

$\begin{array}{llllll}0 & 1 & 2 & 3 & 4 & 5\end{array}$

Plant \# 5

$\begin{array}{llllll}0 & 1 & 2 & 3 & 4 & 5\end{array}$

4. TOTAL VITALITY (considers parameters \#1-2 above) Treatment: Clover

Tomato Variety:

Plant \# 1

\begin{tabular}{lllll}
\hline 0 & 1 & 2 & 3 & 4
\end{tabular}

Plant \# 2

$\begin{array}{lllll}0 & 1 & 2 & 3 & 4\end{array}$


$\begin{array}{llllllll}\text { Plant \# } 3 & 0 & 1 & 2 & 3 & 4 & 5\end{array}$

$\begin{array}{lllllll}\text { Plant \# } 4 & 0 & 1 & 2 & 3 & 4 & 5\end{array}$

$\begin{array}{lllllll}\text { Plant \# } 5 & 0 & 1 & 2 & 3 & 4 & 5\end{array}$

Treatment: Control

Tomato Variety:

Plant \# 1

$\begin{array}{lllll}0 & 1 & 2 & 3 & 4\end{array}$

Plant \# 2

$\begin{array}{llllll}0 & 1 & 2 & 3 & 4 & 5\end{array}$

Plant \# 3

$\begin{array}{llllll}0 & 1 & 2 & 3 & 4 & 5\end{array}$

Plant \# 4

$\begin{array}{llllll}0 & 1 & 2 & 3 & 4 & 5\end{array}$

Plant \# 5

$\begin{array}{llllll}0 & 1 & 2 & 3 & 4 & 5\end{array}$

Treatment: Black Plastic

Tomato Variety:

Plant \# 1

$\begin{array}{llllll}0 & 1 & 2 & 3 & 4 & 5\end{array}$

Plant \# 2

$\begin{array}{llllll}0 & 1 & 2 & 3 & 4 & 5\end{array}$

Plant \# 3

$\begin{array}{llllll}0 & 1 & 2 & 3 & 4 & 5\end{array}$

Plant \# 4

$\begin{array}{llllll}0 & 1 & 2 & 3 & 4 & 5\end{array}$

Plant \# 5

$\begin{array}{llllll}0 & 1 & 2 & 3 & 4 & 5\end{array}$

